Volume 8. No. 8, August 2020

International Journal of Emerging Trends in Engineering Research

Available Online at http://www.warse.org/IJETER/static/pdf/file/ijeter50882020.pdf

https://doi.org/10.30534/ijeter/2020/50882020

\title{
Vehicle Blind Spot Monitoring Phenomenon using Ultrasonic Sensor
}

\author{
Adnan, Z. ${ }^{1}$, Hassan, M. Z. ${ }^{2}$, Ab Wahab N. ${ }^{3}$, Najib, S.M. ${ }^{4}$, Nasir, N.S ${ }^{5}$ \\ ${ }^{1}$ Fakulti Kejuruteraan Mekanikal, Universiti Teknikal Malaysia Melaka, Malaysia, \\ M041910036@student.utem.edu.my \\ ${ }^{2}$ Fakulti Teknologi Kejuruteraan Mekanikal dan Pembuatan, Universiti Teknikal Malaysia Melaka, Malaysia, \\ zahir@utem.edu.my \\ ${ }^{3}$ Fakulti Teknologi Kejuruteraan Mekanikal dan Pembuatan, Universiti Teknikal Malaysia Melaka, Malaysia, \\ norfariza@utem.edu.my \\ ${ }^{4}$ Fakulti Teknologi Kejuruteraan Elektrik dan Elektronik, Universiti Teknikal Malaysia Melaka, Malaysia \\ suhaila.najib@utem.edu.my \\ ${ }^{5}$ Fakulti Teknologi Kejuruteraan Mekanikal dan Pembuatan, Universiti Teknikal Malaysia Melaka, Malaysia, \\ nsyuhada_mn@yahoo.com
}

\begin{abstract}
This paper evaluates a conceptualization of Vehicle Blind Spot Monitoring System (VBMS), which performs a more effective approach in eliminating blind spot of the driver. The newly developed smart blind spot monitoring system simply focusing on an advancement of the preceding work, along with compromising user compatibility and cost-effectiveness. Compact design, reliable and low-cost that contributes to a highly affordable safety feature are the flagship of this new system. Components selection is the main role in constructing an inexpensive blind spot detection system in the present work. Thus, Arduino UNO R3 model and HC-SR04 ultrasonic sensors were employed for the VBMS system due to reasonable market price. Plus, the ultrasonic sensor has demonstrated a remarkable performance in the past blind spot detection system application. Concerning easy installation as well as maintenance on any vehicle, the VBMS is designed as a compact device which assembles the main control unit and sensory parts in a single body to be located at the bottom of the side mirror. Meanwhile, the hazard-warning signal is separately located at the passenger compartment for easily visible by the driver. The angle and sensing range of sensors are both adjustable but vital as their projections define the blind spot limit accurately by characterizing low to a high potential hazard. At the end of this work, a complete VBMS functional prototype of has been establish which effective for real traffic on-road experimentation, with various conditions specified (static, various speed, and overtaken). From the data collected, all targets of the present work have been attained regarding monitoring phenomenon shown by the new-built system. Both pros and cons of VBMS are discussed for further improvement ideas on product development.
\end{abstract}

Key words: Arduino, blind spot, monitoring sensor, ultrasonic sensor

\section{INTRODUCTION}

Throughout driving course, the vital thing is for the driver to obtain information about the changing position of other vehicles on the road to ensure a safe condition from road accidents and traffic jams. Nonetheless, with the help of side mirrors either does not covers the entire area around the vehicle to be seen straight by the driver, as the rear quarter area on both sides of the vehicle are outside the side mirror's reflection view. This is referred to as blind spot of the vehicle [1]. The blind spot is crucial at a certain condition whereby driver fails to detect the presence of hazard as other vehicle enters the blind spot area, due to the structural elements of the vehicles that limits a full assessment of the road situation [2]. This is the primary cause of vehicle crashes that mostly happens towards motorcyclist, which also has been proven by simulation analysis that blind spot happens to be a contributing factor towards the rider visibility problem, other than view obstruction and high speed [3]. Besides that, the blind spot phenomenon may vary in effect of several factors like driver's height and vehicle's size. Plus, large vehicles come up with wider blind spot around the vehicle due to the height difference with standard-sized vehicles. Regards to this issues, special techniques which effectively tested in India were expressed in term of assisting driver as a decision-maker, by considering the parameter of rear view mirror and potential impact to diminish the blind spot area of heavy vehicles [4].

Nowadays, considering the safety factor, numerous car manufacturers in the worldwide have made a headway by equipping this technology on their cars with various ways, 
initiated by Blind Spot Information System (BLIS) for Volvo, Audi Side Assist (ASA) for Audi and Blind Spot Monitoring (BSM) used by Mitsubishi, Toyota and Mazda as well. In an advanced automotive application, Vehicle Anti-Lock Braking System (ABS) is possibly taken in control accordingly by the incorporation of an ultrasonic sensor and Control Area Network (CAN) Bus protocol to prevent collision [5]. Unfortunately, it is estimated that until 2016, only $3 \%$ of vehicle sales in Malaysia are manufactured with this technology feature, which is technically little to none [6]. While back in two years ago, the first test for blind spot technology has been commenced by the New Car Assessment Programme for South East Asian Countries (ASEAN NCAP), conducted on ten ASEAN popular car models but none among them are of Malaysia's product [7]. This shows that the demand for Malaysian vehicle manufacturers to include this safety equipment on our local products is at a crucial state.

Many approaches have been attempted to tackle the blind spot phenomenon such as a camera-based system that used several stages for image processing but encounters a big issue regarding insufficient images for extraction, that contributes to false and missing detections issue [8]. The panoramic view that provides extra safety information also may be useful if the distortion issue and slower performance regarding this work can be solved [9]. Thus, a simple processing approach via optical flow has been demonstrated in compromising a real-time safety alarm, without database usage [10, 11, 12], even a different technique through detection of shadows in daytime and headlamps in night-time had been attempted for faster detection but requires two different algorithms [13]. Another project proposed a hybrid algorithm detection system, designed to bring both efficiency and accuracy, which consumes a fish-eye camera for a wide-angle view and software combination to defines the incoming hazard, but not experimentally proved [14]. A different complex deep learning approach need to be employed in achieving a vision detection that is powerful towards environmental light intensity and shadow factor, which demonstrated up to $97.56 \%$ system's accuracy [15].

In short, the most favourable challenges that keep playing around in a vision-depending blind spot system are image distortion that resulting in false alarm and complex system configuration. This convinced the use of electromagnetic or ultrasonic radar detectors, whereby the operation does not restrict in the day or night time. Hence, this work aims to develop a functional prototype of a smart blind spot monitoring system for all types of vehicles. The Vehicle Blind Spot Monitoring System (VBMS) targeted to provide a simple configuration but with zero warning failure since this safety feature may be attributed to lives and severe damage matters. The prototype was tested in real road traffic with engagement of the Perodua Axia 1.0 model as a testing vehicle.

\section{RELATED WORKS}

\subsection{Ultrasonic sensor applications}

The ultrasonic sensor had been used for wide applications due to easy implementation, ultimately reduces the cost matter at the same time offers fast operation. The ultrasound wave used is categorized as a frequency wave beyond $20 \mathrm{kHz}$ up to Gigahertz, which is too high to be audible by the human's ear [16]. A work regarding ultrasonic sensor application on remotely controlled robots had observed excellent distance measuring accuracy for avoiding single solid and uniform-shaped obstacles [17], plus the ability to control the movement of autonomous robots effectively [18]. Furthermore, this sensor in combination with a potentiometer may help in searching for available parking slots in shopping malls for instance, via an online server system [19]. A great project regarding automatically operated sewerage management had demonstrated efficient river blockage removal by determining the height of accumulated waste using sensors inside a designed platform [20]. These studies show that short distance measurement can be performed well by the ultrasonic sensor in various ways from the small to bigger applications.

\subsection{Arduino-based sensor for blind spot detection}

A Vehicle Blind Spot System (VBSS) prototype device proposed by [21] is an example of which blind spot detection that employs the Arduino control unit and the ultrasonic sensors which are ultimately cheaper than the electromagnetic radar. The system has been effectively tested on the real road condition and successfully detected vehicle that entering the blind spot zone. Nevertheless, as similar to currently used BSM radar technology in the automotive industry, the VBSS distributed components installation around the car body still upholds a complexity issue. Wiring, parts assembly and warning behaviour need to be critically compromised for an additional equipment that is user-friendly. Hence, the contributions of this work will be attributed to a compact-designed system for easy installation as well as maintenance purpose, low cost and high effectiveness not only for hazard detection but to monitor the risk levels as a driver's co-pilot.

\section{METHODOLOGY}

\subsection{Establishment of Design Concept}

The new product design concept for the overall system's structure acquires compact and flexible as the main criteria. The compact or simpler design associated with optimum use of component device and body assembly, make it easier to be 
installed or 'add-on' to the current vehicle as well as maintenance purposes. Meanwhile, the flexibility concept drives a highly compatible blind spot coverage so that any mid-sized vehicle type may be equipped with this technology. The system's internal measure is a key role in the performance of these properties. Figure 1 presents an overview of VBMS's flow process.

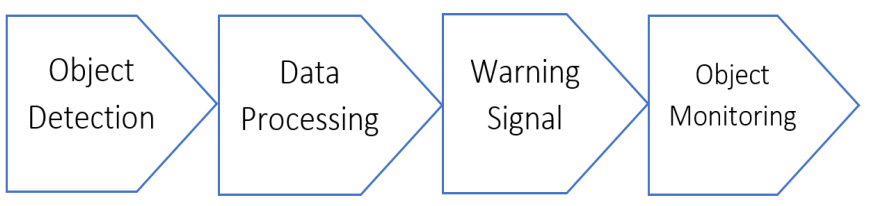

Figure 1: VBMS workflow

The system begins with object detection in the blind spot limit which depending on distance of sensor propagation, in this case, the ultrasonic sensors. At this instant, the data signal is sent to the control unit to be processed. The Arduino controller takes over the process of identifying the hazard and make a decision. If the hazard is confirmed, a warning signal will be blinked to alert the driver about the incoming object. During final stage, the extra information provided to the driver regarding the hazard risk level via object monitoring based on the distance measured by a sensor within the blind spot zone, until it disappears. This monitoring technique used is similar to numerous Arduino-ultrasonic projects as the distance measurement determines different output behaviour, including sensing operation for liquid levelling [22, 23].

\subsection{Characterization of Internal Measures}

\subsubsection{Sensing range set up and program sketching}

Beginning the setting up process, blind spot zone limit of the testing vehicle was specified first as the main part in developing the warning system which involves variables like viewing angles and vehicle model sizes [24], which is why the real-condition measurement on vehicle is important as demonstrated in Figure 2 (a). Meanwhile, an illustration in Figure 2 (b) expresses the right side of the vehicle with specific sensing range values, which being pre-determined in the coding program. These values may vary in accordance with vehicle size.

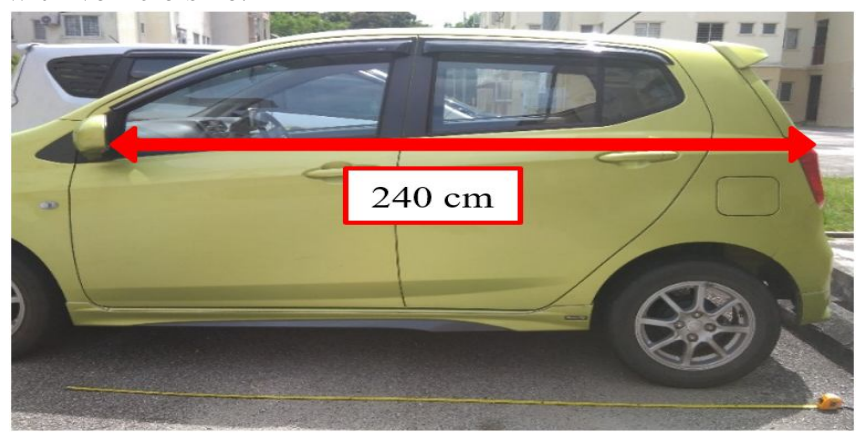

(a)

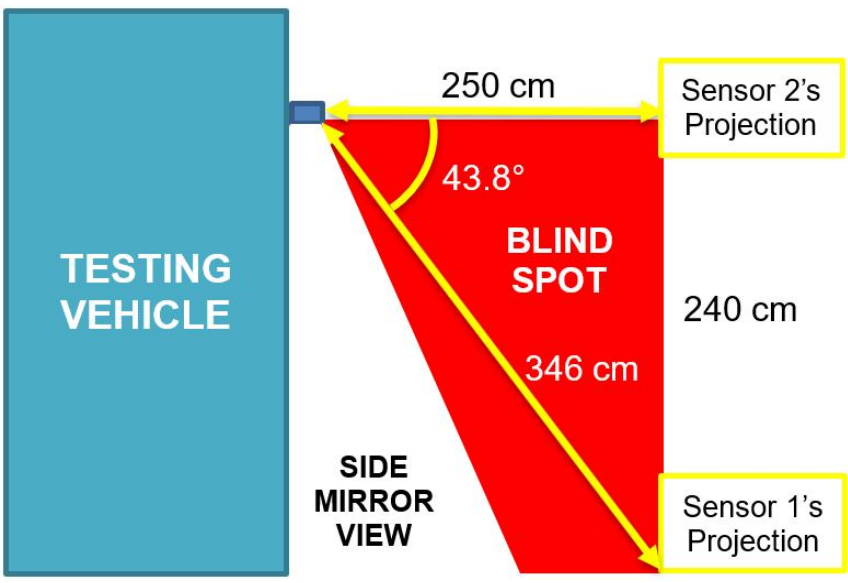

(b)

Figure 2: (a) Measuring the vehicle parameter, (b) VBMS sensing range on Perodua Axia model.

At first, $2.5 \mathrm{~m}$ sensing range for Sensor 2 was set according to the minimum width of standard road. By obtaining the Sensor 2 sensing distance and the measured value from side mirror to the back end of the car, Sensor 1 sensing range and propagation angle can be calculated accordingly, which acts precisely within the set-up parameter.

An Arduino Integrated Development Environment (IDE) that compatible with Arduino Uno R3 was used for the construction of programming code, enabling the serial input from sensors and LEDs to be transferred to the Arduino board instantly via Universal Serial Bus (USB) cable. C++ language was used for programming code, where it measures the parameters and functions to be controlled while monitoring hazard, including the sensing range that determines the VBMS warning behaviour's. The coding sketch uses 'step ()' and 'loop ()' as the preparation and execution orders, respectively. The loop function that makes the following codes continuously repeated after every one complete execution [25], which is important to provide real-time monitoring. This part is responsible for the data processing stage and to activate the alarm behaviour, based on the sensing range.

\subsubsection{Design modelling and simulation for system functional validation}

Figure 3 describing a complete wiring diagram of the new VBMS on TinkerCad, the online-free Arduino simulator, allows the simulation to be run on the completed circuitry for functional-checked purposes. The written program code from the IDE software is used in the simulation test whether all the components involved could work with the coding program in order to pass the test before uploaded to Arduino controller set. This theoretical test is taken as a base standard for the overall connection and coding synchronization, and detects even a single misconnection and locates the source of error specifically. It is simple to use and very practical for system 
validation to be applied in the real application. This process also provides the overall design that enhances the researcher's view for creating simplified system connectivity.

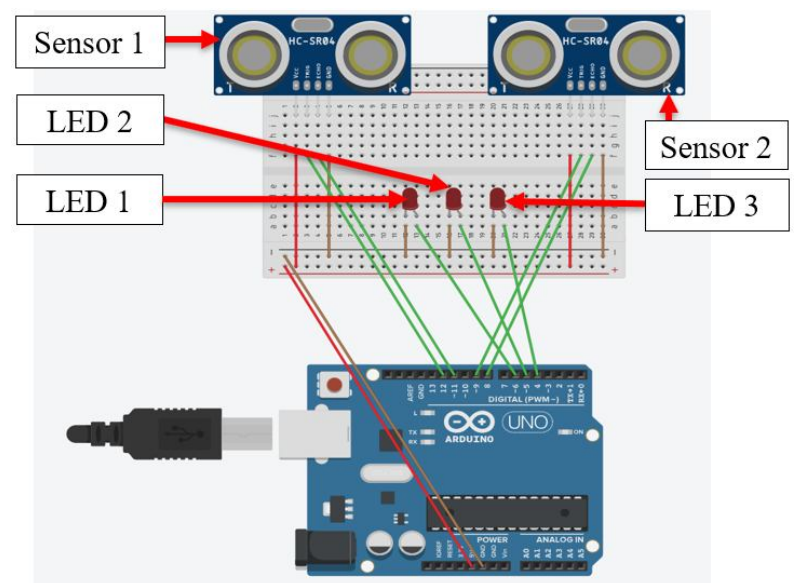

Figure 3: Schematic circuit of VBMS simulation

Here, once the system connects with power supply, both ultrasonic sensors emit the ultrasound wave within a specific range and sense for the distance of the presence obstacle to be transferred to the processing unit. In the meantime, the LEDs blink with different behaviour when the obstacle moved within the sensing range, as controlled by the processor based on distance value calculated. These processes are repeated continuously until the system is powered off. Four pins are equipped on HC-SR04 sensor, namely 'Voltage at the Common Collector (VCC)' for power supply, 'Trig' for impulse trigger, 'Echo' for impulse receiver, and 'Ground (GND)' for ground connector. The pin connection for program code to the control unit system is summarized in Table 1. All sensors and LEDs serial input and output which are the positive terminals are connected to the Arduino digital pins according to their associated PIN, while the negative terminal referred to as the ground connection. As one misleading is enough to cause total fatality, these connections are arranged in a sequence of the number of pins for easy reference thus preventing system malfunction in the VBMS performance test.

Table 1: Pin connection to Arduino board

\begin{tabular}{|l|c|c|c|c|c|}
\hline Pin/Terminal & $\begin{array}{c}\text { Sensor } \\
1\end{array}$ & $\begin{array}{c}\text { Sensor } \\
2\end{array}$ & $\begin{array}{c}\text { LED } \\
1\end{array}$ & $\begin{array}{c}\text { LED } \\
2\end{array}$ & $\begin{array}{c}\text { LED } \\
3\end{array}$ \\
\hline VCC & $5 \mathrm{~V}$ & $5 \mathrm{~V}$ & - & - & - \\
\hline TRIG & 12 & 9 & - & - & - \\
\hline ECHO & 11 & 8 & - & - & - \\
\hline GND & GND & GND & - & - & - \\
\hline POSITIVE & - & - & 6 & 5 & 4 \\
\hline NEGATIVE & - & - & \multicolumn{5}{|c|}{ GND } \\
\hline
\end{tabular}

\subsection{Development of Device Prototype}

3.3.1 Sensing unit operation, compatibility, and
limitations

Firstly, the sensory part of the system was chosen which is an ultrasonic sensor HCSR-04 module as shown in Figure 4, to be correlated with the Arduino set. Utilizing 5V Direct Current (DC) to emit a $40 \mathrm{kHz}$ sonar wave, this sensor performs a non-contact, high accuracy range of distance detection between $2 \mathrm{~cm}$ to $500 \mathrm{~cm}$ range [26]. To operate, it emits an ultrasound that referred to as trigger wave which bounces back upon hitting an obstacle, called an echo wave. Due to Doppler effect, the reflected echo may be distorted from $40 \mathrm{kHz}$ depending on the movement of the reflecting object but as long as the vibration does not being smaller than echo frequency, the effect is negligible [27]. In the new VBMS system, the coupling ultrasonic sensors work together in characterizing the incoming obstacles. These sensors plays different roles based on direction of projection for each to eliminate the blind spot but assembled in a single body.

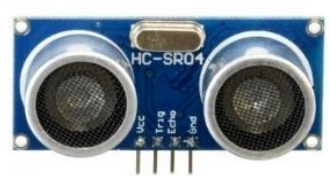

Figure 4: HC-SR04 Ultrasonic Sensor

Upon one complete cycle of wave travel, the time taken gained is a twofold of the distance between sensor and obstacle resulting from triggered sound wave that travel forward and bounce backward to the receiver. The distance calculation are as prescribed by (1) and (2).

$$
\begin{aligned}
& V_{\text {sound }}=331.5+0.6\left(T_{\text {aig }}\right) \\
& V_{\text {sound }}=\frac{d_{0-z}}{t_{\text {waus }}}
\end{aligned}
$$

where, $\boldsymbol{V}_{\text {sound }}$ is speed of sound $(\mathrm{m} / \mathrm{s}), \boldsymbol{T}_{\text {air }}$ is temperature of air $\left({ }^{\circ} \mathrm{C}\right), \mathscr{d}_{\mathbb{Q}-g}$ is distance from sensor to obstacle $(\mathrm{m})$, while $t_{\text {wane }}$ is sound wave time travel (s). Considering $20^{\circ} \mathrm{C}$ as the normal ambient temperature $\left(\overline{\boldsymbol{T}}_{\text {eir }}\right)$, the calculated value of $V_{\text {sound }}$ is equivalent to $340 \mathrm{~m} / \mathrm{s}$. Finally, the distance is obtained accordingly by (3).

$$
d_{\text {armal }}=\frac{340 t_{\text {waws }}}{2}
$$

where $d_{a c t u a l}$ is the actual sensor-to-obstacle distance $(\mathrm{m})$. Through the division of the distance calculated by 2 , the correct distance value between sensor and detected object is finally obtained. In general, the temperature of air within 
detected range affects the accuracy of measurement, since the sound speed is strongly dependable on both temperature and humidity conditions [28]. The VBMS system has been programmed for a sustained normal environment. Note that the speed of sound is directly proportional to the temperature as much as $0.6 \mathrm{~m} / \mathrm{s}$ per $1{ }^{\circ} \mathrm{C}$ [29]. Consequently, the detected entity will be measured nearer in elevated temperature and vice versa. Plus, the RH changes also may vary the measurement by $0.036 \%$ for every $10 \%$ RH change although it is not very significant under normal weather condition. To ensure a highly dependable measurement, both sensor body and ambient temperatures should be equivalent. Hence, the installing location of this new device was set under the vehicle side mirrors, to protect the sensors from sunray since it is an outside installation, thus preventing the body from heat exposure. The warning signal was separately placed in the passenger compartment, at which easily visible by the driver during hazard monitoring.

\subsubsection{Correlation of main processing unit with alarm signal}

Of the various electronics controller unit from the market survey, Arduino UNO model R3 shown in Figure 5 is selected due to small size, cheap, but offers sufficient processing memory as well as digital input and output pins for the VBMS system. In terms of functionality, this device has been effectively employed in measuring, controlling, and displaying data using appropriate components and systems for particular purposes [30]. Arduino is an open-source computer device equipped with an ATmega328 microcontroller with $20 \mathrm{MHz}$ generating speed and 16-bit enumeration specification [31], as a distance measuring meter for VBMS. This easy-to-use platform also provides the most basic functional digital device development for interaction with the environment by sensors and actuators [32].

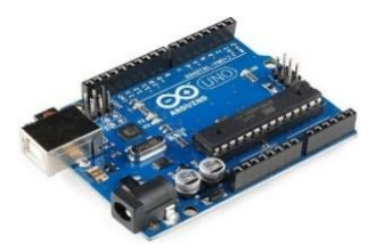

Figure 5: Arduino UNO R3

The Arduino Uno R3 receives the data signals sent from ultrasonic sensor, runs the uploaded program codes, and controls the output signal during the whole monitoring activity. Prior to most conventional radar detectors, a visual alarm is an effective way in monitoring both static and dynamic objects but requires additional parts such as servo motor and Liquid Crystal Display (LCD) [33], which also lengthen the coding task and running elapse if being applied to the present work. Thus, the researcher proposed a multi-LED approach designed for visual signal, interfacing with Arduino processor and providing information from low to high potential hazards as in a metering level which is called 'hazard meter', that will be explained in Section 4.2.

\subsection{Design Finalization and Installation for Testing}

In the end stage, a complete and functional prototype of VBMS has been established throughout all involving methods, as shown in Figure 6 (a) which is readily available for on-road experimentation. In term of component assembly, past researcher demonstrated the use of a Bluetooth module for an efficient wireless data transportation between separately placed sensor and control unit to avoid complexity and plenty of wiring [23]. In light of this problem, a simpler approach has been taken into account whereby the main circuit of smart VBMS assembles both control unit and sensors into one body, thus cutting costs from an additional component and promotes ease of production.

The VBMS device was mounted on the side mirror of Perodua Axia as shown in Figure 6 (b). As illustrated in Figure 2 earlier, Sensor 1 is directed to area limit where the incoming vehicle begins to enter the designated hazard zone, while Sensor 2 that directed perpendicular to the side mirror observes the other end of the blind spot limit. It deactivates all warning signals upon detection to ensure the LEDs stop blinking as soon as the detected vehicles getting out of the monitored area, which can be seen by the driver. Also, the false alarm can be distinguished in certain cases of static object detection. The LED warning signal located inside the vehicles will provide information regarding the hazard condition to the driver. Dual-sensor system in an ultrasonic distance measurement also has been applied by [21] for the blind spot detection and [34] for characterizing the type, speed, and amount of vehicle, whereby both agreed that such way does improve the capability of the sensor compared to intrinsic usage. In this case, the VBMS can differentiate between static objects, i.e., wall, building, with the function of cancelling sensor (Sensor 2), and moving object, i.e., vehicle, pedestrian, via triggering sensor (Sensor 1), thus removing the false signal occurrence.

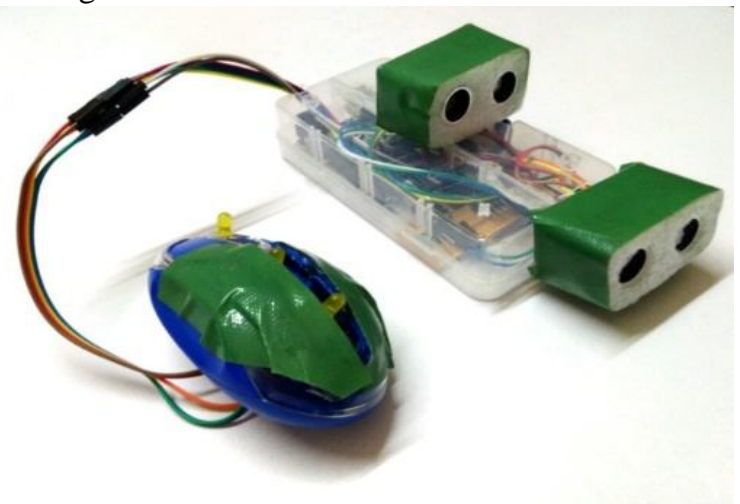

(a) 


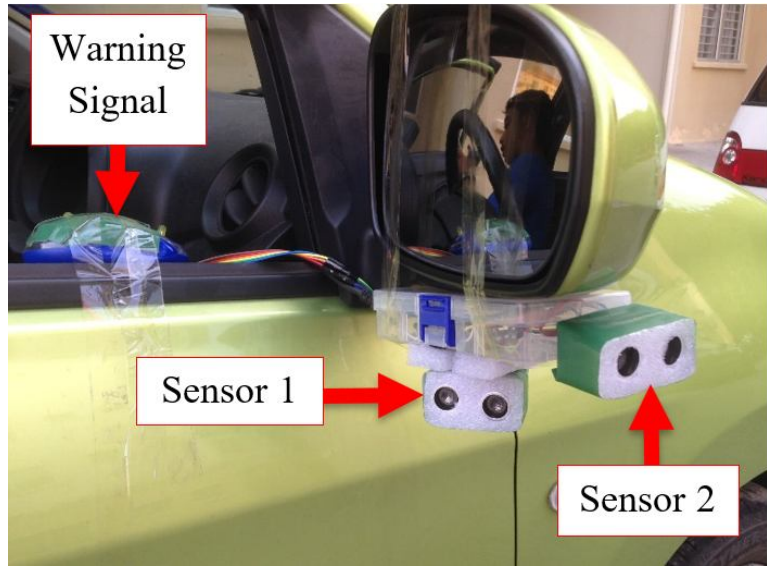

(b)

Figure 6: (a) Prototype of VBMS, (b) Installation for on-road testing

\section{RESULT AND DISCUSSION}

\subsection{Static Test}

This test aims to observe the ability of VBMS device in differentiating between static or moving entity, which allows removing false alarm occurrence that causes distraction and confusion to the driver about surrounding vehicles condition. Sensor 1 works by triggering LEDs warning signal if there are potential risk objects such as vehicles enters the blind zone, not the static objects such as divider and building which is detected by Sensor 2. Figure 7 shows that all LEDs at the hazard meter were deactivated during the test. All the LEDs were turned off when the system detects a building although it is in the blind spot range.

This condition is attributed with the function of Sensor 2 as a 'cancelling sensor', which also may be considered as controlling the Sensor 1. Thus, as long as the detected object is in the Sensor 2 sensing range which directed perpendicular to the car's forward direction, Sensor 1 will be deactivated. This function also provides the benefit of preventing the alarm from triggering unnecessarily, in case of the detected vehicle is approaching forward to overtake and moving out of the hazard zone, which has been inside the driver's view.

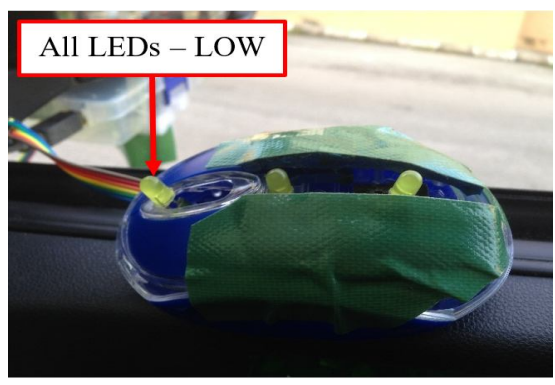

Figure 7: Static Test

\subsection{Speed Test}

The speed test was conducted as the vehicle driven in varied speed condition, which at $60 \mathrm{~km} / \mathrm{h}, 80 \mathrm{~km} / \mathrm{h}$ and $110 \mathrm{~km} / \mathrm{h}$. This is because there is a huge difference regarding the real situation although the prototype has succeeded in lab testing. For a reliability factor, it is crucial for the system provide a good performance in operating at various speed levels such as $60 \mathrm{~km} / \mathrm{h}$ and $80 \mathrm{~km} / \mathrm{h}$, which are standard speed levels in rural as well as city areas, while $110 \mathrm{~km} / \mathrm{h}$ is the maximum speed limit for highways route. A motorcycle was set as a controlled variable, with varying the position inside the hazard zone during the data observation. By considering the worst-case scenario, the performance of this prototype device towards larger vehicles is more convincing if it succeeded in this test. The examples of warning signal behaviour during the speed test were as shown in Figure 8, for day and night time.

The VBMS hazard meter defines the potential risk from low to high risk to help the driver on decision-making before taking action, where the warning indications are such as follows:

i. First LED is HIGH: Hazard is presence but at low risk due to safe distance from a collision, and certain parts of the hazard may be seen through the side mirrors. ("Watch your side mirror.")

ii. First and second LEDs are HIGH: Hazard is presence at a moderate risk, which is usually completely unseen through the side mirrors. ("Do not change your car position.")

iii. All three LEDs are HIGH: Hazard is presence at the highest risk, which is too close to collision and still unseen through the side mirrors. ("Slow down. Let the hazard be gone first.")

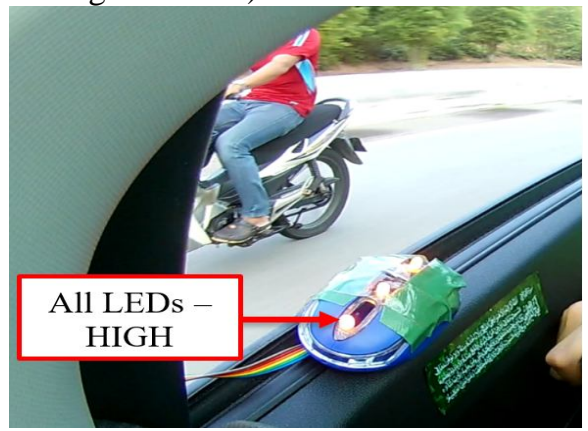

(a)

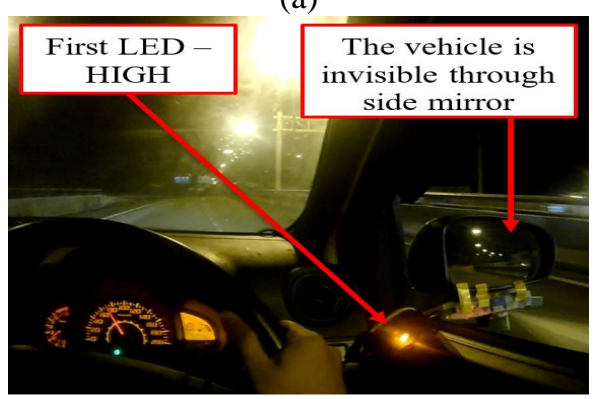

(b)

Figure 8: Speed test during; (a) day-time; (b) night-time 
As observed from Figure 8 (a), the hazard meter activated all three LEDs, indicating a very high risk for an accident to occur if the drivers decide to take actions such as changing lanes or overtaking. While in Figure 8 (b), the first LED on the hazard meter is $\mathrm{HIGH}$, telling that a vehicle just entered the blind spot, which is invisible through the side mirror. Sometimes in this condition, half part of the approaching vehicles is still visible to the driver. The outcome from this test shows a good performance of the ultrasonic sensor in determining the distance of detected obstacles. In another distance measuring test conducted within $4 \mathrm{~m}$ range, the HC-SR04 sensor performance is described as having $98 \%$ accuracy and $100 \%$ precision [35].

\subsection{Overtake Test}

The vital element during on-road driving is to ensure an effective inter-vehicular communication especially in multiple lanes driving, for the drivers to be well-informed upon another vehicle's change in position and speed as proven by simulation in the previous study [36]. This test narrows the VBMS performance test on the different behaviour of approaching vehicles on the highways, where the multiple lanes of road condition promotes more overtaking action between vehicles.

As shown in Figure 9 (a) and (b), no false alarm detected for both overtaking conditions. As a hazard alarm signal, the sensors must be able to distinguish either the monitored vehicle is overtaking which is less hazard potential, or it really staying inside the blind spot area. As observed, the VBMS warning signal were not activating false alarm when another vehicle enters the blinds spot at high speed due to a delay set up in the program code.

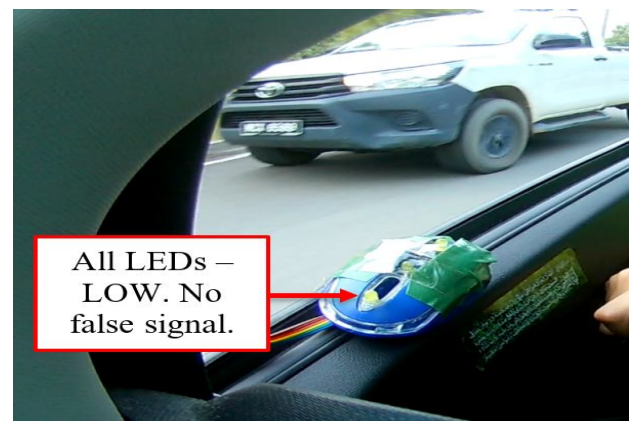

(a)

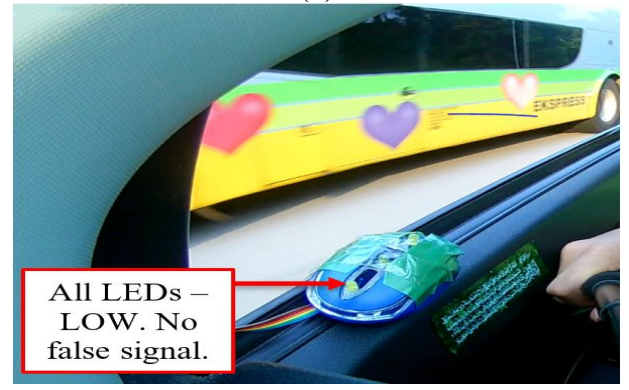

(b)

Figure 9: Test for overtaken by (a) Car and (b) Bus.

\subsection{Performance Analysis}

As all tests have been finished, the data accomplished were tabulated for further analysis. The result of VBMS performance in each conditions and times are presented in Table 2.

Table 2: Overall Test Result

\begin{tabular}{|c|c|c|c|}
\hline Test & Condition & Day & Night \\
\hline 1 & Static & Pass & Pass \\
\hline 2 & Speed $-60 \mathrm{~km} / \mathrm{h}$ & Pass & Pass \\
\hline 3 & Speed $-80 \mathrm{~km} / \mathrm{h}$ & Pass & Pass \\
\hline 4 & Speed $-110 \mathrm{~km} / \mathrm{h}$ & Pass & Pass \\
\hline 5 & Overtake & Pass & Pass \\
\hline
\end{tabular}

All criteria that are required in every testing condition have been fulfilled by the prototype device, with zero false signal occurrence. Furthermore, this safety sensor can differ between buildings and approaching vehicle, performs well at various speed ranges and the behaviour of approaching vehicles was effectively monitored. The newly designed blind spot detection system has successfully eliminates the blind spot area around the Perodua Axia. However, it is found that during the whole test was conducted, the LEDs were not blinking constantly while monitoring the motorcycle as shown in Figure 10, which indicated that the ultrasonic sensors were having difficulty in detecting irregular surfaces.

The angle of wave incidence is one of several factors that responsible for the preciseness of ultrasonic sensor [29], in which this reflected echo may have deteriorated away from the spectacular wave due to smooth reflecting material that either having sound absorption ability or with shape that in such way could deteroriates the sound waves reflection away from the receiver [14]. This may be attributed to the detection of motorcycle and rider's body during the warning signal. For instance, the utilization of a high-spec ultrasonic sensor ranging up to $10 \mathrm{~m}$ in the Adaptive Cruise Control (ACC) system has performed well in an attempt on a fully autonomous mode car during testing in a busy traffic area. However, the irregularities of road and pedestrian behaviour resulting to false pulse during the first finding, but after setting up a moderate threshold distance, the problem was solved [37]. For the VBMS device, the LEDs must keep blinking as long as the hazard stays within fix range of blind spot area. Therefore, this could be overcome by using a high-quality sensor to offer a chance of improvement on the system's overall performance.

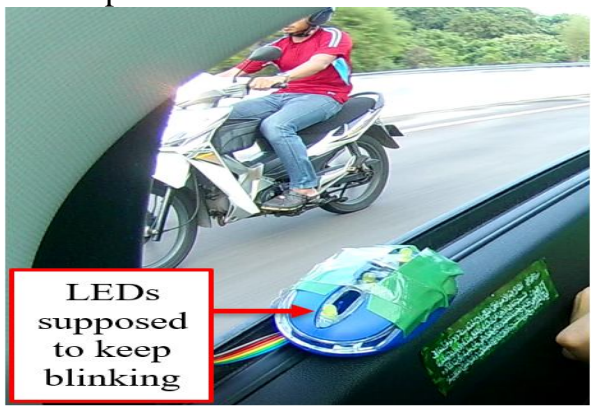

Figure 10: Discontinuous warning signal 


\section{CONCLUSION AND RECOMMENDATION}

The smart Vehicle Blind Spot Monitoring System (VBMS) system has demonstrated the ability to eliminate the blind spot phenomenon. This newly developed device has good potential as a vehicle safety feature in order to improve the awareness among drivers regarding the presence of hazard around their vehicle. VBMS had been made in simple component system configuration, consisting a single control unit that combines two other component functions collaborating with each other. The procedure of device development was done carefully according to sequence for software to hardware components. Hence, no flaw or skipped step happened until the final stage of production. The software system performed real-time processing without lagging due to fewer components involved, plus the sensing distance adjustment was very practical via IDE software to be equipped on different vehicle sizes.

The best suitable sensor chosen had provided true information for the driver in various speed and vehicle conditions tested during the day and night time. The complete VBMS prototype has been considered achieving great cost-effectiveness in terms of components, installation, and the functionality offered towards a vehicle road-driving safety. Looking towards the future, the new designed VBMS system could be improvised in term of sensor quality, as the ultrasonic sensor cannot measure through walls, vacuum, high pressure or temperature, a high repetition rate, and unable to measure accurately in vapour environment. Applying a higher quality sensor to this system will provide the reliability in various conditions including off-road as well as four weather seasons in the overseas.

\section{ACKNOWLEDGMENT}

The authors would like to thank the support and guidance given by Faculty of Mechanical and Manufacturing Engineering Technology, Faculty of Electrical and Electronic Engineering Technology, Universiti Teknikal Malaysia Melaka (UTeM), Malaysian Institute of Road Safety Research (MIROS) and ASEAN NCAP secretariat through ASEAN NCAP Collaborative Holistic Research (ANCHOR II) programme. This work had been carried out through the grant of FRGS/2018/FTKMP-AMC/F00387.

\section{REFERENCES}

[1] B. Maitra, M. F. Cheranchery, and P. Prasad, Rules for safe driving, in Training Manual for Drivers, 2017, ch. 4, pp. 69-109.

[2] P. O. Bresnev, A. V. Tumasov, D. V. Zeziulin, D. M. Porubov, and L. N. Orlov, Development of a detection road users system in vehicle A- pillar blind spots, in Proc. IOP Conf. Ser.: Mater. Sci.
Eng., 2018, pp. 1-8.

[3] D. Farooq and J. Juhasz, Simulation analysis of contributing factors to rider visibility issues for car-motorcycle accidents, Period. Polytech. Transp. Eng., pp. 1-7, April 2019.

[4] P. Pitchipoo, D. S. Vincent, N. Rajini, and N. S. Rajakarunakaran, COPRAS decision model to optimize blind spot in heavy vehicles: A comparative perspective, Procedia Eng., vol. 97, pp. 1049-1059, Dec. 2014.

[5] N. K. A and K. Venkatasubramanian, Intelligent collision avoidance system at blind spots or sharp turns, School of Electronics Engineering, VIT University, Chennai, India, 2015.

[6] M. H. M. Isa, Blind spot technology must be seen, The Sun, pp. 1-2, April 2016.

[7] J. Lee, ASEAN NCAP organises first blind spot monitor test, Paul Tan, 2018. [Online]. Available: https://paultan.org/2018/03/07/asean-ncap-organises -first-blind-spot-monitor-test/.

[8] D. Kwon, R. Malaiya, G. Yoon, J. Ryu, and S. Pi, A study on development of the camera-based blind spot detection system using the deep learning methodology, Appl. Sci., vol. 9, pp. 1-20, July 2019.

[9] M. W. Park, K. H. Jang, and S. K. Jung, Panoramic vision system to eliminate driver's blind spots using a laser sensor and cameras, Int. J. Intellgent Transp. Syst. Res., vol. 6, pp. 1-14, March 2012.

[10] J. Saboune, M. Arezoomand, L. Martel, and R. Laganiere, A visual blindspot monitoring system for safe lane changes a visual blindspot monitoring system for safe lane changes," in Proc. International Conference on Image Analysis and Processing (ICIAP), 2014, pp. 1-10.

[11] C. Fernandez, D. F. Llorca, M. A. Sotelo, I. G. Daza, A. M. Hellin, and S. Alvarez, Real-time vision-based blind spot warning system : experiments with motorcycles in daytime/nighttime conditions, Int. J. Automot. Technol., vol. 14, no. 1, pp. 113-122, Feb. 2013.

[12] C. Tsuchiya, S. Tanaka, and H. Furusho, Real-time vehicle detection using a single rear camera for a blind spot warning system, SAE Int. J. Passeng. Cars - Electron. Electr. Syst., vol. 5, no. 1, pp. 146-153, May 2012.

[13] B. Wu, C. Kao, Y. Li, and M. Tsai, A real-time embedded blind spot safety assistance system, Int. J. Veh. Technol., pp. 1-15, April 2012.

[14] L. G. C. Iii and A. A. Hernandez, Hybrid detection for vehicle blind spot using fisheye camera : A Framework, in Proc. 4th International Conference on Computing and Applied Informatics (ICCAI), 2019, pp. 250-253.

[15] A. S. Alon, J. L. Dioses Jr., A machine vision detection of unauthorized on-street roadside parking in restricted zone: an experimental simulated barangay-environment, International 
Adnan, Z et al., International Journal of Emerging Trends in Engineering Research, 8(8), August 2020,4357 - 4365

Journal of Emerging Trends in Engineering Research (IJETER), Vol. 8, No. 4, pp. 1056-1061, April 2020.

[16] N. Seckel and A. Singh, Physics of 3D ultrasonic sensors, Toposens GmbH, pp. 1-11, July 2019.

[17] J. Azeta, C. Bolu, D. Hinvi, and A. A. Abioye, Obstacle detection using ultrasonic sensor for a mobile robot, in Prof. IOP Conf. Series: Materials Science and Engineering, 2019, pp. 1-5.

[18] S. Lee, J. Lim, G. Tewolde, and J. Kwon, Autonomous tour guide robot by using ultrasonic range sensors and $Q R$ code recognition in indoor environment, in Proc. IEEE International Conference on Electro/Information Technology, 2014, pp. 410-415.

[19] D. N. Bagenda and C. Parulian, Online information of parking area using ultrasonic sensor through wifi data acquisition, in Proc. IOP Conference Series: Earth and Environmental Science, 2018, pp. $1-7$.

[20] S. Talukder, M. I. I. Sakib, Z. R. Talukder, U. Das, A. Saha, and N. S. N. Bayev, USenSewer : ultrasonic sensor and GSM-Arduino based automated sewerage management, in Proc. CTCEEC Conference Proceedings, 2017, pp. 1-6.

[21] M. Z. Hassan and H. I. Zainal Ariffin, Development of vehicle blind spot system for passenger car, Appl. Mech. Mater., vol. 393, pp. 350-353, Sep. 2013.

[22] V. Raikar, A. Ranjan, P. Poddar, and K. J. Chaitanya, Arduino based smart water level monitoring and controlling for domestic application, Int. J. Res. Eng. Sci. Manag., vol. 2, no. 2, pp. 138-141, Feb. 2019.

[23] M. Husni, D. O. Siahaan, H. T. Ciptaningtyas, H. Studiawan, and Y. P. Aliarham, Liquid volume monitoring based on ultrasonic sensor and Arduino microcontroller, in Proc. IOP Conf. Series: Materials Science and Engineering, 2016, vol. 128, pp. 1-10.

https://doi.org/10.1088/1757-899X/128/1/012026

[24] M. S. M. Hashim, A. H. Ismail, S. Abu Bakar, M. S. Muhamad Azmi, Z. Mohamad Razlan, A. Harun, N. S. Kamarrudin, I. Ibrahim, M. K. Faizi, M. A. M. Saad, M. F. H. Rani, A. R. Mahayadin, M. A. Rojan, M. S. Azizizol and M. H. Md Isa, Identifying blind spot zone for passenger cars using grid-based technique, J. Soc. Automot. Eng. Malaysia, vol. 2, no. 3, pp. 245-251, Sep. 2018.

[25] E. Z. Orji, C. V. Oleka, and U. I. Nduanya, Arduino based door automation system using ultrasonic sensor and servo motor, J. Sci. Eng. Res., vol. 5, no. 4, pp. 341-349, April 2018.

[26] H. R. Hatem, A. I. Abdalla, and Z. N. A. Al-rawi, Design and implementation of ultrasonic radar system for distance measurements using Arduino, Int. J. Eng. Technol., vol. 7, no. 4, pp. 3115-3118,
Jan. 2018.

[27] A. Buachoom, A. Thedsakhulwong, and S. Wuttiprom, An Arduino board with ultrasonic sensor investigation of simple harmonic motion, in Proc. Siam Physics Congress (SPC2019): Physics beyond disruption society, 2019, pp. 1-4.

[28] K. G. Panda, D. Agrawal, A. Nshimiyimana, and A. Hossain, Effects of environment on accuracy of ultrasonic sensor operates in millimeter range, Perspect. Sci., vol. 8, pp. 574-576, July 2016.

[29] V. A. Zhmud, N. O. Kondratiev, K. A. Kuznetsov, V. G. Trubin, and L. V. Dimitrov, Application of ultrasonic sensor for measuring distances in robotics, in Proc. International Conference Information Technologies in Business and Industry, 2018, pp. 1-9.

[30] F. Hidayanti, K. R. Lestari, and R. Anwar, Arduino based conductive silver lamination device, International Journal of Emerging Trends in Engineering Research (IJETER), Vol. 8, No. 2, pp. 265-270, Feb. 2020.

[31] F. Baskoro and B. R. Reynaldo, Detection of lock on radar system based on ultrasonic US 100 sensor and Arduino UNO R3 with image processing GUI, in Prof. IOP Conf. Ser.: Mater. Sci. Eng., 2018, pp. $1-7$.

[32] D. Asemota, Ultrasonic servo motor control with arduino micro-controller, Vellore Institute of Technology (VIT) University, Vellore, India, 2018.

[33] H. K. Ali, J. S. Abdaljabar, and S. M. Abdullah, Design of ultrasonic radar, Int. J. Emerg. Sci. Eng., vol. 3, no. 7, pp. 6-10, May 2015.

[34] R. Stiawan, A. Kusumadjati, N. S. Aminah, M. Djamal, and S. Viridi, An ultrasonic sensor system for vehicle detection application, in Proc. 7th Asian Physics Symposium, IOP Conf. Series: Journal of Physics: Conf. Series, 2019, pp. 1-6.

[35] R. R. S. Bongolan, J. G. M. Eden, E. T. DT. Mendoza, J. K. A. Pancho, and E. C. M. Telan, Ultrasonic distance measuring study, Faculty of $\mathrm{Al}$ Taj International School, Senior High School Department, Riyadh, Kingdom of Saudi Arabia, 2019.

[36] G. Bulumulle and L. Bölöni, Reducing side-sweep accidents with vehicle-to-vehicle communication, J. Sens. Actual Networks, vol. 5, no. 19, pp. 1-16, Dec. 2016.

[37] L. Alonso, V. Milanes, C. Torre-ferrero, J. Godoy, J. P. Oria, and $T$. de Pedro, Ultrasonic sensors in urban traffic driving-aid systems, Sensors, vol. 11, pp. 661-673, Jan. 2011.

https://doi.org/10.3390/s110100661 